\title{
Panic Attack
}

National Cancer Institute

\section{Source}

National Cancer Institute. Panic Attack. NCI Thesaurus. Code C92620.

An episode of intense fear accompanied by symptoms such as heart palpitations,

sweating and chills or hot flushes, a sensation of dyspnea, chest pain, abdominal distress,

depersonalization, fear of going crazy, and fear of dying. 